\title{
Editorial
}

Digestion

\section{A Further Piece of the Puzzle: Positive FOBT, Colonoscopy, Aspirin and the Prevention of Colorectal Cancer}

\author{
Johann Ockenga \\ Gastroenterology, Endocrinology and Clinical Nutrition, Klinikum Bremen Mitte, Bremen, Germany
}

Colorectal cancer (CRC) is the cause of death in more than 600,000 people worldwide and is one of the most frequent cancers in the Western world. Therefore, the search for effective strategies for prevention or detection of adenomas or early CRC with the potential of cure has a high priority. In several countries the current practised strategies include fecal occult blood testing (FOBT) and/ or screening colonoscopies for the detection of colonic cancer or removal of colonic adenomas (polyps).

One of the most promising agents for chemoprevention is aspirin or a cyclooxygenase-2 (COX-2) inhibitor like celecoxib. In the general population, a significant $26 \%$ reduction in CRC incidence by aspirin intake was demonstrated in studies with a 23 -year follow-up (relative risk (RR) 0.74, 95\% confidence interval (CI) 0.57$0.97)$ [1]. In addition, an analysis of aspirin versus no aspirin in individuals with a history of adenomas or CRC has shown a statistically significant $21 \%$ reduction in risk of adenoma recurrence (RR 0.79, 95\% CI 0.68-0.92) [1]. A very recent study on the long-term effect (56 months) of aspirin on cancer risk in carriers of hereditary CRC (CAPP2 Trial) confirmed this positive effect and reported a reduced risk of CRC (incidence rate ratio 0.56, 95\% CI $0.32-0.99, \mathrm{p}=0.05$ ) [2]. Similar data are available for
COX-2 inhibitors with a statistically significant $34 \%$ reduction in overall adenoma recurrence risk (RR 0.66, 95\% CI 0.60-0.72) and a 55\% reduction in advanced adenoma incidence (RR $0.45,95 \%$ CI $0.35-0.58$ ) in a population of individuals with a previous history of colonic adenomas. However, no data are available for COX-2 inhibitors for the general population [1]. Although these data are promising, it should be mentioned that both aspirin and COX-2 inhibitors are associated with adverse effects like dyspepsia, gastrointestinal bleeding and haemorrhagic stroke (table 1). Therefore, it will still be important to consider the risk-benefit ratio before recommending these agents for general chemoprevention.

Whereas chemoprevention aims to prevent the development of CRC, the use of FOBT and screening colonoscopy target at the early detection of colonic lesions like adenoma or early CRC. It was promptly assumed that early detection and removal of colonic adenomas has the potential to prevent the development of CRC. A systematic review done through the Cochrane Collaboration, examining all CRC screening randomized trials that involved FOBT on more than one occasion, showed that trial participants allocated to screening had a $16 \%$ lower CRC mortality (RR 0.84, 95\% CI 0.78-0.90) [3].

\section{KARGER}

Fax +4161306 1234

E-Mail karger@karger.ch

www.karger.com (c) 2012 S. Karger AG, Basel

$0012-2823 / 12 / 0854-0276 \$ 38.00 / 0$

Accessible online at:

www.karger.com/dig
Assoc. Prof. Johann Ockenga

Gastroenterology, Endocrinology and Clinical Nutrition

Klinikum Bremen Mitte, St.-Jürgen-Strasse 1

DE-28177 Bremen (Germany)

Tel. +49 421 5354, E-Mail johann.ockenga@klinikum-bremen-mitte.de 
Table 1. Incidence of dyspepsia, serious gastrointestinal bleeding, stroke and myocardial infarction in the general population and in a population with aspirin or celecoxib intake [1]

\begin{tabular}{llll}
\hline Dyspepsia & $\begin{array}{c}\text { Serious gastroin- } \\
\text { testinal bleeding }\end{array}$ & Stroke & $\begin{array}{l}\text { Myocardial } \\
\text { infarction }\end{array}$ \\
\hline $\begin{array}{r}\text { Overall risk in a general population } \\
26.8 \%\end{array} \quad 0.24 \%$ & $0.06 \%$ & $1 \%$ \\
\hline $\begin{array}{l}\text { Additional risk for intake of } \\
\text { Aspirin } 18.8 \%\end{array} \quad 0.31 \%$ & $\begin{array}{l}0.02 \% \\
\text { (haemor- } \\
\text { rhagic) } \\
\text { Celecoxib } 18.8 \%\end{array}$ & $0.13 \%$ & $-0.26 \%$ \\
\hline
\end{tabular}

The effect of a flexible sigmoidoscopy was confirmed by a large randomized controlled trial (170,000 subjects) in intention-to-treat analyses, reducing the CRC incidence in the intervention group by $23 \%$ (hazard ratio $0.77,95 \%$ CI $0.70-0.84$ ) and reducing mortality by $31 \%$
(RR 0.69, 95\% CI 0.59-0.82). In per-protocol analyses, adjusting for self-selection bias in the intervention group, the incidence of CRC in people attending screening was reduced by $33 \%$ (RR $0.67,95 \%$ CI $0.60-0.76$ ) and mortality by $43 \%$ (RR $0.57,95 \%$ CI $0.45-0.72$ ) [4].

In this issue of Digestion, Lee et al. [5] present the first results of a prospective observational study about the effect of aspirin intake on the results of screening colonoscopy in a cohort of the National Bowel Cancer Screening Programme (BCSP), launched in England in 2006. The authors describe a lower incidence of colorectal neoplasia of subjects with aspirin intake in an endoscopic bowel-screening population based on positive FOBT. Although the design of this prospective observational study cannot exclude that the lower CRC and adenoma rate might be due to increased false positivity of FOBT related to the higher risk of (occult) gastrointestinal bleeding rate in aspirin users, these data are an additional piece of the puzzle to improve our strategy for an individual recommendation for the prevention of CRC.

\section{References}

$>1$ Cooper K, Squires H, Carroll C, Papaioannou D, Booth A, Logan RF, Maguire C, Hind D, Tappenden P: Chemoprevention of colorectal cancer: systematic review and economic evaluation. Health Technol Assess 2010;14:1-206.

-2 Burn J, Gerdes AM, Macrae F, Mecklin JP, Moeslein G, Olschwang S, Eccles D, Evans DG, Maher ER, Bertario L, Bisgaard ML, Dunlop MG, Ho JW, Hodgson SV, Lindblom A, Lubinski J, Morrison PJ, Murday V, Ramesar R, Side L, Scott RJ, Thomas HJ, Vasen HF,
Barker G, Crawford G, Elliott F, Movahedi M, Pylvanainen K, Wijnen JT, Fodde R, Lynch HT, Mathers JC, Bishop DT, CAPP2 Investigators: Long-term effect of aspirin on cancer risk in carriers of hereditary colorectal cancer: an analysis from the CAPP2 randomised controlled trial. Lancet 2011;378:2081-2087.

$\checkmark 3$ Hewitson P, Glasziou P, Watson E, et al: Cochrane systematic review of colorectal cancer screening using the fecal occult blood test (hemoccult): an update. Am J Gastroenterol 2008;103:1541-1549.
4 Atkin WS, Edwards R, Kralj-Hans I, et al: Once-only flexible sigmoidoscopy screening in prevention of colorectal cancer: a multicentre randomised controlled trial. Lancet 2010;375:1624-1633.

$\checkmark 5$ Lee TJW, Hull MA, Rajasesekhar PT, Clifford GM, Ritchie M, James P, McNally RJQ, Rutter ME, Rees CJ: Aspirin users attending for NHS bowel cancer screening have less colorectal neoplasia: chemoprevention or false-positive faecal occult blood testing? Digestion 2012;85:278-281. 